\title{
Nursing Instructors' Perception of Clinical Education Competencies: A Qualitative Study
}

\section{Shourangiz Beiranvand}

Tarbiat Modares University

Sima Mohammad Khan Kermanshahi ( $\nabla$ sima098@yahoo.com )

Tarbiat Modares University

Robabeh Memarian

Tarbiat Modares University

\section{Research Article}

Keywords: Clinical Competence, Nursing Instructor, Clinical Education

Posted Date: January 7th, 2021

DOI: https://doi.org/10.21203/rs.3.rs-118299/v1

License: (c) (i) This work is licensed under a Creative Commons Attribution 4.0 International License. Read Full License 


\section{Abstract}

Background: Clinical education competencies are a core requirement for clinical nurse instructors, contributing toward better the learning outcomes of students in the clinical settings. Awareness of nursing instructor's perception is essential for designing nursing professional development programs. This study aimed to explore nursing clinical instructors' perception of the essential competencies for clinical education.

Methods: A qualitative design, based on the content analysis approach was used. Eighteen clinical nursing instructors and five nursing students from Lorestan University of Medical Science(LUMS), were selected via a purposeful sampling method. Data were collected using a semi structured in-depth interview method, from October 2018 to February 2019. The interviews were recorded, transcribed verbatim, and analyzed with using Graneheim and Lundman methods.

Results: Analysis of nursing instructors' perceptions of clinical education competencies identified four main categories and eight sub-categories. The main categories included; (I) tasks oriented education; (II) guiding and supporting nursing students; (III) organizing communication skills and (IV) professionalethical role modeling

Conclusions Although academic clinical faculties and part time clinical nursing instructors reported a high level of knowledge and confidence in their ability to establish communication skills, role modeling and nursing students' supervision, Part time clinical nursing instructors, also identified the need for additional support for their clinical teaching roles. They were not prepared enough for clinical teaching roles; their perception of clinical educational skills was tasks oriented education. The development, implementation, and evaluation of curriculum based on clinical competency with structured mentoring processes for part time clinical nursing instructors are recommended, in order to meet the knowledge gap that has been created.

\section{Background}

In the past few decades, competency-based nursing education in higher education contexts emerged as an efficient educational model for training competent nursing students [1]. The advances in medical sciences, the increasing numbers of nursing students, the high expectations of education and health systems, and the transfer of educational systems from hospital-based models to higher education institutes necessitate the development of the professional competencies of nursing instructors [2]. The concept of competence refers to a person's knowledge, skills, and abilities that are essential to effective performance in a job [3]. Nursing competency refers to a person's ability to perform nursing duties effectively to integrate knowledge and emotional and psychomotor skills in nursing care [4].

There are several ways to describe the competence of nurse educators. The World Health Organization (WHO) has identified the core competencies of nursing educators for the development of nursing education in 2016. These core competencies include: " (i) Nurse educators possess a sound 
understanding of contemporary educational theories, principles and models underlying the design of curricula and the value of adult learning; (ii) Nurse educators demonstrate the skills and abilities to design, implement, monitor and manage curricula based on sound, contemporary educational models, principles, and best evidence; (iii) Nurse educators maintain current knowledge and skills in theory and practice, based on the best available evidence; (iv) Nurse educators develop their critical inquiry and the ability to conduct research and utilize findings to identify and solve educational and practice-based problems; (v) Nurse educators demonstrate effective communication skills that promote collaborative teamwork and enhance partnership among health profession educational and clinical practice; (vi) Nurse educators demonstrate professionalism including legal, ethical and professional values as a basis for developing nursing education policies, procedures and decision making; (vii) Nurse educators utilize a variety of strategies to monitor and evaluate nursing programs, the curricula and mastery of student learning; and (viii) Nurse educators demonstrate the skills of system management and leadership to create, maintain and develop desired nursing programs and shape the future of education institutions"[5].

In the American League for Nursing (NLN) has proposed eight main competencies for nursing educators. These competencies including: "(i) Facilitate learning, (ii) facilitate learner development and socialization, (iii) use assessment and evaluation strategies, (iv) participate in curriculum design and evaluation of program outcomes, (v) function as a change agent and leader, (vi) pursue continuous quality improvements in the nurse educator role, (vii) engage in scholarship, and (viii) function within the educational environment [6].The core competencies expressed by WHO and NLN, have focused on the normative standards for the role of nursing educators. These competencies are common to all nursing educators and are not specific to CNIs.

A recent systematic review showed that clinical instructors' competencies are complex and as it constantly changes according to, the healthcare organizational and political structure [7]. Furthermore, organizational restructuring and emphasis on cost effectiveness has transformed the scope of CNIs' practical work and their role in clinical education [3]. Studies have also shown that required competencies for CNls vary between countries [8].

A qualitative study with phenomenological approach showed that the most important competency of nursing clinical instructors from the perspective of nursing students including: establishing communication skills, using coaching techniques for learning, having experience and specialty knowledge and being a role model [9]. In a qualitative study with content analysis, the researchers identified competencies for Finnish health science student teachers, including: competence of knowledge in practice; competence of ethical principles in clinical education; competence of digital technology; competence of communication skills and competence of cultural [3].

Other studies have focused on the challenges that CNIs face while developing their clinical teaching skills. Researchers founded that one of the most important students' clinical learning challenges is incompetency of CNIs, including: insufficient scientific and practical preparation; insufficient clinical caring; insufficient approach in using teaching and assessment strategies [10]. The most important factor 
has attributed to this issue, the shortage of qualified nursing faculty to teach in nursing schools, which is actually three times worse in the clinical setting than in the classroom [11]. One of the innovative strategies for filling, the nursing educator's job vacancies are recruiting part-time CNIs to educate students in clinical setting [12]. They are expert in clinical practice but lack formal knowledge, skills and attitudes to teach and evaluate students, which has negatively affected the development of their successful behaviors in clinical education and the quality of educational experience [13]. They need for supplementary education to update their competencies [14].

In spite of the importance of clinical education, a clear insight into clinical instructor's perceptions about whether they feel competence in their knowledge and how to train nursing students in clinical settings is lacking. Perception of CNIs' experiences in their professional roles is essential to design competency based curriculum for them [15]. Many educational institutions offer orientation programs and workshops, they are often not based on their actual and specific needs. The purpose of this study was to describe CNIs' perceptions of the essential competencies for clinical education.

\section{Methods}

\section{Study design}

This study had a qualitative design with a conventional content analysis approach. A qualitative study to discover participants 'experiences in real environments, rooted of critical realism, that is, searching real knowledge embedded in participants' ideas and perspectives [16]. Content analysis is used as a research method for subjective interpretation of textual data content through regular classification process of coding and identification of subcategories and categories by immersion in the data to achieve new insights [17].

\section{Study Setting}

This study was performed in two educational hospitals affiliated to Lorestan University of Medical Science(LUMS) in Iran. In this context, we categorize the individuals engaged in clinical instruction, include two groups: Nurse clinicians and academic clinical educators. Academic nursing educators who work for an educational institution and provide both direct or indirect supervision, and evaluation of students in the clinical environment. They do not have enough time to provide clinical education to students, also, most of them teach theoretical courses and run research activities. To compensate for the shortage of nursing faculty members, educational institutions hire nurse clinicians with bachelor's or master's degrees in nursing for clinical teaching. A nurse clinician is described with one to several years of clinical experience are being recruited for clinical teaching of students in time slots other than their work shifts on a temporary, semester-to-semester contract basis. They are commonly known as part time clinical nursing faculty.

\section{Participants}


The participants included $18 \mathrm{CNIs}$ (seven male and 11 female) ranging in age from 28 to 50 years and with an educational experience of two to 24 years. Six of the instructors had a PhD in nursing, and $12 \mathrm{had}$ nursing bachelor degrees. Purposive sampling was performed with maximum variation in terms of age, sex and educational and clinical experience at different academic levels. Consequently, based on the results of the initial interviews and to confirm the findings through theoretical sampling, five students in the third to the eighth semesters of the undergraduate nursing program (three female and two male) aged 19 to 23 years were interviewed. The inclusion criterion for the CNIs was having at least two years of clinical education experience, and for the nursing students, having passed at least two clinical education courses.

\section{Ethical considerations}

This study was confirmed by the Ethics Committee of Tarbiat Modares University (Code: IRTMU.REC.1396.728). All the participants were informed about the aim of the study. They were assured that participation in the study is voluntary and their identities not being disclosed in the research reports. For this meaning, a numeric code was assigned to each participant. Finally, we asked the participants to read and sign the study informed consent form.

\section{Data collection}

Semi-structured interviews were held from October 2018 to February 2019 to collect data based on the study objective. The interviews were conducted individually with participants' agreement in a private room at a predetermined time. The interview questions included the following:

1. What kind of competencies do you apply as a nursing instructor in clinical education?

2. Please describe your feelings and perceptions about your role in clinical education.

The interviewer probed, participant responses by using questions or statements, such as "Please elaborate" and "What do you mean?" to explore participants' learning experiences. Totally, 23 interviews were conducted (18 CNIs and 5 nursing students). The interviews were recorded digitally and transcribed verbatim, immediately after the session, each interview last 45-80 min (60 minutes on average). Data saturation was achieved, since no new concepts emerged during the last three interviews.

\section{Data analysis}

Data were analyzed using conventional content analysis according to the proposed steps of Graneheim and Lundman [18]. The analysis of the interview texts began after the first interview and transcription. Each interview was reviewed several times to fully understand the experiences of the interviewees and obtain a general sense of the interview content. The subsequent interviews were conducted based on the results of the analysis of the previous interviews. Then, the content of each interview was broken to basic meaning units, the irrelevant pieces of data were discarded, and the text was coded line-by-line. Interviews resulted in 200 initial codes. These concepts or codes were condensed and abstracted based on their similarities and differences and with the meanings sustained into higher-level sub-categories and categories. 


\section{Trustworthiness}

To assess the trustworthiness of qualitative research, Lincoln and Guba propose a framework to establish the truth value of an inquiry [19].

A: Credibility: The credibility of the study was approved through long-term involvement with the participants and data; peer check; and member check. Long-term involvement with participants helps researchers gain the trust of the participants and a deep understanding of details of the data. A peer check was used to consolidate the credibility of the analysis process. The research team members independently analyzed the interviews, compared the concepts, categories, and themes, and in the case of disagreement, discussed the issue to reach an agreement. A member check was also used to consolidate the credibility of the data. After analyzing each interview, the participants were briefed on the process of analysis of the data and findings and were asked to examine whether the developed concepts reflected their experiences or ideas. Finally, their comments and suggestions were incorporated into the analysis.

B: Confirmability: To ensure the confirmability of the findings, the initial results and the analysis of the findings were presented and revised in a seminar with the research team.

C: Dependability: This indicates that, the findings are accurately aggregated and are not affected by the researchers' error or interests. In this study, the methods of data collection, interviewing, coding, analyzing the data and identifying the content were accurately stated to be judged correctly by the external audit.

D: Transferability: The transferability indicates that the findings are consistent with other contexts. In this study, transferability was approved through rich and deep descriptions of the context, presenting the necessary explanations about participants' perceptions, and using maximum variation sampling methods.

\section{Results}

The data analysis led to the emergence of four main categories, including, tasks oriented education, support and guidance for students, organizing interpersonal communication and professional-ethical role modeling (see Table 1). 
Table 1

Nursing instructors' clinical education competencies: Categories and subcategories

\begin{tabular}{|c|c|}
\hline Categories & Subcategories \\
\hline \multirow[t]{2}{*}{ Tasks oriented education } & - Lack of clinical education development programs. \\
\hline & - inappropriate learning climate \\
\hline \multirow[t]{2}{*}{ Support and guidance for students } & - Providing assistance to students during clinical practice \\
\hline & - Providing effective feedback \\
\hline \multirow[t]{2}{*}{ Organizing communication skills } & - Inter-personal communication skills \\
\hline & - Professional inter-personal skills \\
\hline \multirow[t]{2}{*}{ Professional-ethical role modeling } & - Ethical role modeling \\
\hline & - Professional value role modeling \\
\hline
\end{tabular}

\section{tasks oriented education}

Nursing instructors' perception of educational competencies was predominantly tasks oriented education. It is a practical method to strengthen students' psychomotor skills and less focused on educational objectives in the cognitive and emotional domains. The subcategories of this category were classified as lack of clinical education' development programs and inappropriate learning climate. The majority of the part time CNIs expressed one of the most common reasons for tasks oriented education is lack of preparation programs in clinical teaching role. They emphasized "task-centered" approach to care rather than "patient-centered". Part time CNIs did not use the nursing process in clinical teaching and were not capable of doing so themselves either. One Part-time CNI said:

"Institutions of higher education in nursing do not have orientation programs or workshops about how to clinical teaching for part time CNIs. In case of holding continuing education development programs for us, they were not operational" (P 7).

Another Part-time CNIs said:

"Based on the students' interest, I teach clinical procedures (for example blood pressure and wound care) step by step in accordance with a standard checklist" (P2).

The nursing instructors stated that their clinical environment is mainly oriented task completion, priority was not given to nursing process-based practice, according to learned knowledge of nursing. They revealed that nursing students obeying the nursing staff and perform their duties.

One Part-time CNIs reported: 
"Students find patient care based on the nursing process an excessive and difficult task, because their role models are the nursing staffs, who are tasks-based" (P3).

The students stated that, after graduating and entering the workplace, hospital authorities place greater emphasis on performing clinical skills and procedures rather than managing patient care. They believe that a good nurse is who has good technical skills, in fact, the staff nurses and their task-oriented actions also serve as role models for nursing students.

In this regard, one of the nursing students explains:

"I most like to learn the procedures and techniques when, I look at my career prospects; if I have great theoretical knowledge but don't know clinical practice, the ward head and nursing staff will not accept us" (P5).

Academic clinical educators had experienced more active clinical teaching methods, such as group discussions and case-based clinical education. They believed that the use of these methods in clinical education made students familiar with group collaboration, sharing knowledge, and applying theoretical concepts in clinical practice. Respondents stated that effective group discussions by educators can result to make learning experiences, enjoyable for students.

One academic clinical educator expressed: "I would ask the students to discuss their positive or negative experiences of interning with other students in a clinical conference in a group" (P17).

Another Academic clinical educator explained: "Students identify the patients' needs, and discuss the patient care plan with other students" (P15).

One nursing student approved the academic educators' statements and said:

"The academic clinical educators introduced the cases to us. According to the nursing process, we identified the client's objective and subjective problems by reviewing the patient's file, taking a history and performing a physical examination of the clients. We then designed, implemented, and evaluated the nursing care plan for them. This method led to effective and lasting learning" (P5).

Academic nursing educators in this context do not have enough time to provide clinical education to students because of having to teach theoretical courses and run research activities. Also, most of them are on nursing PhD scholarships and are away from clinical practice. We found that these groups of academic clinical educators were rare and the majority of clinical educators in this context were part-time CNIs.

\section{Guiding and supporting students}

CNIs' perception the competencies of clinical education, guiding and supporting students through providing effective feedback and assistance during clinical practice. They believe that providing 
assistance in the clinical settings promotes learning and enhances students' self-confidence and independence. In this regard, one Part-time said:

"First, I perform special and sensitive procedures of patient care myself and the students observe my performance; then, they perform the clinical procedures themselves; I monitor and encourage their positive performance to boost their self-confidence and make them become independent in their learning activities" $(P 9)$.

Also CNIs reported that providing feedback to students, about their performance in a timely and regular manner was an effective feedback strategy. It supports the students toward good clinical practice. In this regard, academic clinical educator adds:

"Feedback immediately after each procedure and without the nursing staff, patients and patient companions noticing will help the students to develop self-esteem and enhances their learning of clinical skills" (P16). A part-time CNI approved academic educators' statements and said:

"Feedback should be given clearly after every clinical practice which will help the students in learning clinical procedures which will avoid further mistakes and harm to the patient" (P8).

\section{Organizing communication skills}

CNIs perception of communication competence included categories: inter-personal skills and professional inter-personal skills. They described open, honest inter-personal skills with students as important facilitators in students learning. One Part time CNIs describe: "The first day of clinical education is orientation day. I communicate respectfully with students, Introducing the students with the clinical setting, equipment, personnel, internship rules"

$(P 7)$.

CNls stated that teaching students about honest interpersonal skills with clients and the health care team will lead to better patients care and the development of care plan for them.

Academic clinical educator explains: "teaching students in relation to therapeutic communication with patients leads to identifying patients' needs and designing a care plan based on their needs" (P18).

The Part-time clinical instructors, who belonged to the same clinical units, considered clinical experiences as the most important factor for their communicating with the healthcare team. They believed that good communication with the care team lead to students' acceptance and greater cooperation of the staff in the students' clinical education. In this regard, a Part-time CNI said "... I am an experienced clinical nurse and belong to the same clinical setting. So, it is easier for me to communicate with the nursing staff and the healthcare team in the area of work' $(P 1)$.

The other Part-time CNI participant said: "Communicating with the nursing staff will lead to a positive attitude towards me and my students, which will subsequently increase the efficiency of the internship" ( $\mathrm{P}$ 
6).

But, from point of view academic clinical educators, scientific expertise was the most important factor in their communication with the healthcare team. One academic clinical educator described her experience as: "I can communicate with the nursing staff by sharing knowledge on update topics in concerning the provision of nursing care to patients" (P 17).

The students also noted that the relationship between CNIs and nursing staff in the clinical settings can create an intimate atmosphere, improve clinical skills and increase the efficiency of the internship. They identified nursing staff as a resource for learning about clinical practice. A nursing student described the benefits of good relationships with the clinical staff:

"When we performed a clinical practice the wrong way, nursing staff taught us the correct method of performing the procedure be because a good relationship may be helpful in this situation"(P4).

\section{Professional-ethical role modeling}

Role modeling is one of the hallmarks of instructors' competences in clinical practice to convey professional attitudes and behaviors to students. CNIs reported that they were functioning as a role model for the students. They believed that having passion and a positive attitude to the nursing profession is very important in students' interest to the nursing profession. A Part-time CNI stated:

"I take care of the patients with passion and enthusiasm; I consider the patients part of my family. I believe that convey the perception and mindset, about my profession to the students" (P12).

CNIs reported that clinical education through role modeling has a profound effect on promoting the students' professional values and ethical features by observing their behavior. They acknowledged that nursing students learn professional values such as accountability, professional commitment, respecting to the patients' beliefs and values and maintaining confidentiality in caring for the patients by modeling after their clinical education.

Academic clinical educator states:

"If I demonstrate respect to the patients' beliefs and values, students would naturally behave in a similar manner to those people" (P15).

Part-time CNI explained:

"At the end of the internship hour, I realized that the patient's IV line was broken; although the internship time was over, I stayed with the student to replace the patient's IV line so that the student would learn, responsibility, and professional commitment" (P11).

\section{Discussion}


Clinical education provides an opportunity for nursing students to apply the theoretical knowledge in real settings [20], so paying attention to CNIs' perception of clinical education competencies is important.

The first category, included subcategories that reflected tasks-oriented education by part-time CNIs. Although part-time CNIs, may be experts in clinical practice and, it does not mean that they are proficient in clinical training. They need a range of educational skills during the transition to CNI [21]. A study showed that less than half of the CNIs knew themselves as qualified educator in clinical teaching [22]. The findings of another study, revealed that many CNIs considered the clinical education as a series of routine tasks that it did not meet students to educational outcomes [23]. The experiences of the majority of nursing students in other studies conducted in this context showed that there is a gap between theoretical knowledge and clinical practice [24]. Researchers in a systematic review found that educators with lower degrees generally preferred to use traditional teaching approaches [25].

Clinical education based on nursing process, enhances students' critical thinking in care based on clientcentered approach. Lack of attention to the nursing process in the clinical education course is also evident and considerable in other studies in this context [20]. In this study, unlike the part time instructors, academic clinical educators used effective modern methods, such as holding clinical conferences and case-based education. They have an important role in supporting students to understand meaning in clinical practice, and facilitate post-clinical-conference discussions. These methods are considered a creative strategy for facilitating nursing students' education that enhances their skills in nursing care delivery [26]. The results of a previous study showed that case base learning was a desirable experience for nursing students that strengthens critical thinking skills and helps students to acquire professional skills by creating a desirable learning environment [27]. The majority of nursing instructors in this study part time CNIs who had entered the academic setting without any formal preparation for teaching and learning. The lack of training can adversely affect clinical instructors' effectiveness; therefore, taskedbased clinical education had become their main approach. Obviously, they might need to develop teaching competencies through the design of a curriculum for them.

Another finding of this study showed that clinical instructors support students in clinical settings to achieve learning outcomes, which is consistent with a previous study [28]. Another study showed that nursing students did not receive effective feedback from their CNIs. Proper feedback as a facilitator of students' learning is essential in the success of clinical education; error reduction and patient safety guarantee [29]. In this study, clinical instructors' perception of clinical education was task-oriented therefore, they provide effective feedback to students during clinical practice to achieve this outcome.

Clinical support increased the students' motivation, reinforced their professional identity, improved their attitude toward the profession, and accelerated their socialization process [30]. The results of a qualitative study revealed that most students in clinical settings had difficulty in finding help when needed, especially in faced with clinical difficult situations. It had a negative impact on their clinical skill learning, motivation, and attitude [31]. These differences could be due to differences in the concept of 
support in studies. The main reason for the support and guidance of instructors for the students' learning in this study was continuous presence of instructors to supervise the students in clinical settings.

Another competence of nursing instructors was communication skills, these included: Inter-

personal skills and Professional inter-personal skills. A review of the literature showed that the ability to develop interpersonal relationships with students were the most valuable competence for CNIs, which led to a positive clinical learning environment [32]. Interpersonal relationships with students, leads to their' achievement of learning outcomes and the satisfaction of the students [33].

In this study, most CNIs were expert clinical personnel and belonged to the clinical setting, thus more easily communicated with the healthcare team. Communicating with nursing staff increases students 'learning, motivation and self-confidence. Poor communication with the healthcare team hinders nursing instructors' achievement of clinical education objectives and leads to the distrust of the nursing staff to the nursing students [34]. The WHO (2016) also stressed that health science teachers should have effective communication with the healthcare team to promote interdisciplinary collaboration in health and education care [5].

Academic clinical educators also interacted with the healthcare team by sharing their specialized knowledge. Similarly, in the study McSharry et al (2010) CNIs were a source of learning for the nursing staff. They informed nursing staff about evidence-based nursing care, which it helped to their acceptance and credibility in clinical settings [35]. Therefore, educational institutes when hiring CNIs, it is important to pay attention to two characteristics, namely their scientific expertise and clinical experience.

The participants considered professional-ethical role modeling as one of their competencies for the transfer of experiences, attitudes and professional values to the students. The results of a systematic review showed that ethical aspects were considered the most important elements of the competence of health science educators [7]. In clinical settings, instructors have two essential roles: One as a good nursing role model and another as a good teaching role model. In fact, instructors are committed to the professional roles of both nurses and teachers simultaneously [36]. The lack of role models can lead to increased stress and dissatisfaction among nursing students in educational and clinical settings [37]. As educators' ethical competence significantly affects students' experience of teaching [38]. In this study, nursing educators emphasized their ethical characteristics and professional values as role models for students. Nursing instructors in this context are Muslim. The Quran, Muslims' Holy Book, has also stressed the importance of role models in dimensions of spiritual and ethic.

\section{Limitations}

All of the participants shared their experiences about competencies for clinical education. Educational systems vary from country to country therefore; the present findings cannot be generalized to international educational contexts. Nonetheless, clinical educators from other countries are expected to 
share the challenges identified in this study to find appropriate interventions in their curricula for the clinical education of students in clinical settings.

\section{Conclusion And Implication For Practice}

This study provided an insight into the perception of CNIs about their competencies in clinical education as experienced and expressed by them. The findings are valuable in identifying the requirements to improve CNIs' competence by helping educational managers to improve educational standards. This study has contributed to evidence-based knowledge through an accurate qualitative method, which should facilitate educational structures to meet the changing needs and improve educator's practices, environments and effectiveness.

Although academic clinical faculties and part time clinical nursing instructors reported a high level of knowledge and confidence in their ability to establish communication skills, role modeling and supporting nursing students, Part time CNIs, also identified the need for additional support for their clinical teaching roles. They were not prepared enough for clinical teaching roles; their perception of clinical educational skills was tasks oriented education. There is a need to support in continuing education and training in a targeted manner. According to the results of this study, it is recommended: First, the development, implementation, and evaluation of competency based curriculum with structured mentoring processes for clinical nursing instructors are recommended, in order to meet the knowledge gap that has been created. Second, nursing education institutions shall employ a mentor with educational and clinical experiences to prepare part time CNIs for the roles and responsibilities of clinical education according to the designed programs.

\section{Abbreviations}

WHO

World Health Organization; CNIs:Clinical Nursing Instructors; NLN:National League for Nursing

\section{Declarations}

\section{Authors' contributions}

SMk, SB, and RM mad the designing of study, SB and RM participated in data collection, and data analyzed by all authors. All the authors contributed adequately to the completion of this study. All authors have read and approved the manuscript.

\section{Competing interests}

No conflict of interest has been declared by the authors.

\section{Funding}


The study was funded and supported by Tarbiat Modares University about the financial support, confirming the project after reviewing, and issuing the credit to data collection

\section{Acknowledgments}

The authors express their gratitude to the clinical nursing instructors and students involved in this research for sharing their experiences with the researchers. This paper was extracted from nursing doctoral dissertation and has been approved by research deputy of Tarbiat Modares University, so The authors appreciate all the officials of mentioned research deputy.

\section{Ethics approval and consent to participate}

This study was confirmed by the Ethics Committee of Tarbiat Modares University in Tehran, Iran (Code: IR-TMU.REC.1396.728). All participants granted written informed consent to participate in the study. All methods were carried out in accordance with relevant guidelines and regulations.

\section{Availability of data and materials}

The data and all supporting materials used in our manuscript are freely available to any scientist wishing to use them from the corresponding author on request.

\section{Consent for publication}

Not Applicable.

\section{References}

1. Zlatanovic T, Havnes A, Tveiten S. Nurse teachers' perceived competencies in the context of students' first clinical placements: A qualitative study. J Nurs Educ Pract. 2017;7 (1):32-44. doi:10.5430/jnep. v7n1p32

2. Ariana $M$, Soleimani $M$, Oghazian MB. Job satisfaction and the factors affecting satisfaction in nurse educators: A systematic review. J Prof Nurs. 2018; 34(5):389-99. doi.org/10.1016/j.profnurs.2018.07.004

3. Kuivila HM, Mikkonen K, Sjögren T, Koivula M, Koskimäki M, Männistö M, et al. Health science student teachers' perceptions of teacher competence: A qualitative study. Nurse Educ Today. 2020;84: doi:10.1016/j.nedt.2019.104210

4. Moghabghab R, Tong A, Hallaran A, Anderson J. (2018). The difference between competency and competence: A regulatory perspective. Journal of nursing regulation, 9(2):54-59.doi:10.1016/S21558256(18)30118-2

5. World Health Organization. Nurse educators core competencies. 2016. https://www.who.int/hrh/nursing_midwifery/nurse_educator050416.pdf. Accessed October 20, 2019. 
6. National League for Nursing. Certified nurse educator (CNE) Candidate Handbook. 2019. http://www.nln.org/docs/default-source/default-document-library/download-the-certified-nurseeducator-(cne-)-examination-candidate-handbook-(pdf).pdf?sfvrsn=0

7. Mikkonen K, Ojala T, Sjögren T, Piirainen A, Koskinen C, Koskinen M, et al. Competence areas of health science teachers: A systematic review of quantitative studies. Nurse Educ Today 2018; 70 : 77-86.doi:10.1016/j.nedt.2018.08.017

8. Salminen L, Stolt M, Saarikoski M, Suikkala A, Vaartio H, Leino-Kilpi H. Future challenges for nursing education: A European perspective. Nurse Educ Today. 2010;30(3):233-8. doi:10.1016/j.nedt.2009.11.004

9. Niederriter JE, Eyth D, Thoman J. Nursing students' perceptions on characteristics of an effective clinical instructor. Sage Open Nursing. 2017;3. doi: 10.1177/2377960816685571

10. Baraz S, Memarian R, Vanaki Z. Learning challenges of nursing students in clinical environments: A qualitative study in Iran. J Edu Health Promot. 2015; 4(52). doi:10.4103/2277-9531.162345

11. American Association of Colleges of Nursing. Nursing faculty shortage fact sheet. Washington, DC: Rosseter R.2020. http://www.aacnnursing.org/News-Information/Fact-Sheets.

12. Sorrell J.M, Cangelosi PR. Expert clinician to novice nurse educator: Learning from first-hand narratives. Springer Publishing Company, United States. 2015. https://core.ac.uk/download/pdf/147840312.pdf

13. Wenner TA, Hakim AC. Role transition of clinical nurse educators employed in both clinical and faculty positions. Nurs Educ Perspect. 2019;40(4):216-21. doi: 10.1097/01.NEP.0000000000000468

14. Glynn DM, McVey C, Wendt J, Russell B. Dedicated educational nursing unit: Clinical instructors role perceptions and learning needs. J Prof Nurs. 2017;33(2):108-12.

doi:10.1016/j.profnurs.2016.08.005

15. McPherson S. Part-time clinical nursing faculty needs: An integrated review. J Nurs Educ. 2019;58(4):201-206. doi: 10.3928/01484834-20190321-03

16. O'Brien BC, Harris IB, Beckman TJ, Reed DA, Cook DA. Standards for reporting qualitative research: A synthesis of recommendations. Acad Med. 2014;89(9):1245-51 doi:10.1016/j.nedt.2019.104210.

17. Hsieh, H.-F. and S.E. Shannon, Three approaches to qualitative content analysis. Qual Health Res 2005. 15(9):1277-88. doi:10.1177/1049732305276687

18. Graneheim UH, Lundman B. Qualitative content analysis in nursing research: concepts, procedures and measures to achieve trustworthiness. Nurse educ today. 2004; 24(2):105-112. doi:10.1016/j.nedt.2003.10.001

19. Speziale HS, Streubert HJ, Carpenter DR. Qualitative research in nursing: Advancing the humanistic imperative. Lippincott Williams \& Wilkins; 2011.

20. Jasemi M, Whitehead B, Habibzadeh $H$, Zabihi RE, Rezaie SA. Challenges in the clinical education of the nursing profession in Iran: A qualitative study. Nurse Educ Today. 2018;67:21-26.

doi:10.1016/j.nedt.2018.04.010. 
21. Owens RA. Part-time nursing faculty perceptions of their learning needs during their role transition experiences. Teach Learn Nurs. 2017; 12(1):12-16. doi:10.1016/j.teln.2016.10.002

22. Oprescu F, McAllister M, Duncan D, Jones C. Professional development needs of nurse educators. An Australian case study. Nurse Educ Pract 2017; 27: 165-8. doi:10.1016/j.nepr.2017.07.004

23. Sadeghi A, Oshvandi K, Moradi Y. Explaining the inhibitory characteristics of clinical instructors in the process of developing clinical competence of nursing students: A qualitative study. J Family Med Prim Care. 2019; 8(5):1664. doi:10.4103/jfmpc.jfmpc_34_19

24. Bazrafkan L, Najafi Kalyani M. Nursing Students' experiences of clinical education: A qualitative study.Inves educ enferm. 2018; 36(3):e04. doi:10.17533/udea.iee.v36n3a04

25. Koivula M, Tarkka M-T, Simonen M, Katajisto J, Salminen L. Research utilisation among nursing teachers in Finland: a national survey. Nurse educ today. 2011;31(1):24-30. doi:10.1016/j.nedt.2010.03.008

26. Li S, Ye X, Chen W. Practice and effectiveness of "nursing case-based learning" course on nursing student's critical thinking ability: A comparative study. Nurse Educ Pract. 2019; 36:91-96. doi:10.1016/j.nepr.2019.03.007

27. Gholami M, Saki M, Toulabi T, Kordestani-Moghadam P, Hossein Pour AH, Dostizadeh R. Iranian nursing students' experiences of case-based learning: A qualitative study. J Prof Nurs. 2017;33(3):241-249. doi:10.1016/j.profnurs.2016.08.013

28. Phuma-Ngaiyaye E, Bvumbwe T, Chipeta MC. Using preceptors to improve nursing students' clinical learning outcomes: A Malawian students' perspective. Int J Nurs Sci. 2017; 4(2):164-168. doi:10.1016/j.jjnss.2017.03.001

29. Aliafsari Mamaghani E, Rahmani A, Hassankhani H, Zamanzadeh V, Campbell S, Fast $O$, et al. Experiences of Iranian nursing students regarding their clinical learning environment. Asian Nurs Res 2018; 12(3):216-222. doi:10.1016/j.anr.2018.08.005

30. Joolaee S, Farahani MA, Amiri SRJ, Varaei S. Support in clinical settings as perceived by nursing students in Iran: a qualitative study. Nurs Midwifery Stud. 2016; 5(1):e31292. doi:10.17795/nmsjournal31292

31. Kaphagawani NC, Useh U. Clinical supervision and support: Exploring pre-registration nursing students' clinical practice in Malawi. Ann Glob Health. 2018; 84(1):100-109. doi:10.29024/aogh.16

32. Collier AD. Characteristics of an effective nursing clinical instructor: The state of the science. J Clin Nurs. 2018; 27(1-2):363-374. doi:10.1111/jocn.13931

33. Nguyen VN, Duke M, Forbes H. Nurse educator confidence in clinical teaching in Vietnam: A crosssectional study. Collegian. 2018; 25(3):335-340. doi:10.1016/j.colegn.2017.09.008

34. Dahlke S, O'Connor M, Hannesson T, Cheetham K. Understanding clinical nursing education: An exploratory study. Nurse Educ Pract. 2016; 17:145-152. doi:10.1016/j.nepr.2015.12.004

35. McSharry E, McGloin H, Frizzell AM, Winters-O'Donnell L. The role of the nurse lecturer in clinical practice in the Republic of Ireland. Nurse Educ Pract. 2010; 10(4):189-195. doi:10.1016/j.nepr.2009.08.0 
36. Karimi Moonaghi H, Dabbaghi F, Oskouie S, Vehviläinen-Julkunen K, Binaghi T. Teaching style in clinical nursing education: A qualitative study of Iranian nursing teachers' experiences. Nurse Educ Pract 2010; 10: 8-12. doi:10.1016/j.nepr.2009.01.016

37. Mokhtari Nouri J, Ebadi A, Alhani F, Rejeh N, Ahmadizadeh MJ. Qualitative study of humanizationbased nursing education focused on role modeling by instructors. Nurs Health Sci 2013; 15(2): 13743. doi:10.1111/j.1442-2018.2012.00732.x

38. Salminen L, Stolt M, Metsämäki R, Rinne J, Kasen A, Leino-Kilpi H. Ethical principles in the work of nurse educator-a cross-sectional study. Nurse educ today. 2016;36:18-22. doi:

10.1016/j.nedt.2015.07.001 